\title{
Research on Cross-Cultural Management Strategy of Enterprises of Northeast Asia Based on the Belt and Road Initiative
}

\author{
Jing Huang ${ }^{1, *}$ Guang Wang ${ }^{1}$ Bingxuan Wang ${ }^{1}$
}

${ }^{1}$ International Institute of Business Administration, Jilin International Studies University, Changchun, Jilin, China

*Corresponding author. Email:2694284122@qq.com

\begin{abstract}
This article uses Hofstede's cultural dimensions theory to illustrate the importance of cross-cultural management of enterprises from power distance, uncertainty avoidance, individualism or collectivism, masculinity vs femininity, and short-term or long-term orientation, takes the enterprises of Russia, Japan, and South Korea in China as the research objects, and proposes countermeasures and suggestions for the cross-cultural management of enterprises of Northeast Asia.
\end{abstract}

\section{Keywords: cross-cultural management strategy, enterprises of Northeast Asia, the Belt and Road Initiative}

\section{INTRODUCTION}

Since 2015, "the Belt and Road Initiative" has been implemented for 5 years according to the principle of common consultation, sharing and joint development. In the past five years, the cultural exchange between China and the West, enterprise cooperation and national cooperation have achieved good results. However, with the development of enterprise cooperation of "the Belt and Road Initiative", cross-cultural management issues are gradually emerging. Under the influence of COVID-19 worldwide, the current international market is not as stable as that in the past, and it is more difficult for enterprises to develop the international market. In the ever-changing international market, enterprises with different cultural or national backgrounds need to optimize their internal management to achieve efficient operation and reduce costs. To solve the difficulties of cross-cultural management is an effective means to realize the efficient operation of enterprises and reduce the operating costs of enterprises.

This paper will take Japanese enterprises, South Korean enterprises and Russian enterprises in China as examples, and give suggestions on strategy research through the influence of Hofstede's cultural dimensions theory on organizations, including five aspects.

- power distance: it refers to the degree of unequal distribution of power in society or organization. The greater the power distance is, the more obvious the situation of centralization will be.

*Fund: Research on human resource development and Innovation of Enterprises in Northeast Asia base on the "Belt and Road" Initiative special funded by Jilin International Studies University in 2020 (JWKY2020JSZD005)
- uncertainty avoidance: whether it can accept the uncertainty of planned events, and whether the society is subject to uncertain events and ambiguous environmental threats when considering its own interests, and whether uncertainty is avoided and controlled through formal channels;

- individualism vs collectivism: whether individual interests or collective interests are put in the first place, whether the society pays attention to the interests of the individual or the collective;

- masculinity vs femininity: whether there is gender preference. whether the division of labor between men and women has obvious historical traces;

- long-term vs short-term orientation (in a later phase of the study)

\section{RUSSIAN CULTURE AND THE DILEMMA OF CROSS-CULTURAL MANAGEMENT OF ENTERPRISES}

According to Hofstede's research, Russia belongs to a country with high power distance. However, from Russia's historical development and recent trends, Russia also has the characteristics of revolution, and those in power are more frequently questioned and challenged. For the uncertainty avoidance, Russia's tradition is to avoid uncertainty. The low acceptance of uncertainty is also one of the reasons that affect Russia's economic development. The influence of Russian masculinity on management culture is weak. Russia is a country with a low degree of masculinity. It 
respects the equality of men and women, and also respects that women have the same rights as men. According to Hofstede's research data, China's masculinity score is 66, while Russia's score is only 36. Historically, Russia is a country inclined to individualism, but after years of interaction with China, it has also begun to be inclined to collectivism. The uncertainty of global economic form makes Russia more dependent on government or related assistance in social security, welfare and education. In recent years, due to the instability of global economy and the uncertainty avoidance in Russian culture, short-term orientation is biased from the perspective of decisionmaking, which is different from traditional Chinese culture.

There are similarities between Russian culture and Chinese culture, but the problems or difficulties in the cross-cultural management of enterprises mainly lie in the differences between the two cultures. First of all, the communication of information is the difficulty in cross-cultural management. Russia is a "low-context" country, while China is a "high-context" country. In the enterprise management, most Russian employees will directly express their dissatisfaction with their work when they are not satisfied with their work. On the contrary, Chinese employees don't express their dissatisfaction directly. Secondly, in the process of management, Russian managers tend to convey information directly and accurately, while Chinese managers convey information with extended meaning. For the management process, the Chinese managers tend to manage the process, and the Chinese employees are more accustomed to completing a task under the supervision of the leader, and have low self-motivation; the Russian managers tend to manage the results and give employees more autonomy in the management, and employees have higher autonomy. Finally, the dissemination scope of information is also very different in the two countries. In "low context", there is a high requirement for the accuracy of information dissemination, and the scope of information related to work is limited to work and separated from personal life. In "high context", the information covers a wide range and involves information related to personal life, and it is easy to cause offense to the Russian side, thus easily forming contradictions in communication between the two sides.

\section{JAPANESE CULTURE AND THE DILEMMA OF CROSS-CULTURAL MANAGEMENT OF ENTERPRISES}

Japan is deeply influenced by Chinese Confucian culture. Japanese cultural characteristics have many similarities with Chinese culture, but there are different values for the cognition of things. Similarly, according to Hofstede's research, Japan is a country with high power distance, and Japan's power concentration is higher than that of China, which means that Japan is a country with a strict hierarchy. The Japanese life etiquette also reveals respect for the power. For example, when two parties have a meeting, a large bow represents low power, and a small bow represents high power. When the two parties exchange business cards, only those with high status can decide whether to exchange business cards. If the person with high status refuses, the exchange of business cards fails. The title and position on the business card need to be very accurate. After the business card is exchanged, the other party will make the same level of courtesy according to the title and position on the card. Masculinity is more obvious in Japanese culture. In terms of social division of labor, women are more likely to be full-time housewives. Work is generally done by men. In recent years, with the continuous integration of Western culture, women have more power. From the perspective of the gender of corporate executives, males are the majority, and the number of female executives is increasing. Japan is also a collectivist country, focusing on collective interests. The lifetime employment system is a characteristic of Japanese companies. Japan is a state that highly avoids uncertainty. The strict, meticulous, and persistent characteristics of Japanese culture make it difficult to accept the occurrence of uncertain events. Japanese culture also pays more attention to the long-term orientation. Similar to China, under the influence of economic uncertainties, there has been a tendency to focus on short-term changes in recent years.

Japanese enterprises in China also have difficulties in cross-cultural management. If the CEO or person in charge of a Japanese-funded enterprise is Japanese, and other employees of the enterprise are mainly Chinese, Chinese employees will not be fully trusted, corporate bureaucracy is serious, fairness is poor, and factional struggles are fierce. From the perspective of communication, Chinese employees are not familiar with Japanese culture and will be interpreted by the Japanese side as not respecting each other due to lack of courtesy. The historical issues between the two countries can easily cause prejudice between the two sides and increase the difficulty of communication. Due to Japan's rigorous, meticulous, and serious cultural characteristics, there are differences in performance appraisal standards, making it difficult for Chinese employees to hold long-term positions, and the personnel loss of Japanese-funded enterprises is serious. For example, if the person in charge of a Japanese-funded enterprise in China is Chinese, the enterprise is usually a joint-venture enterprise. The Japanese side will prefer to choose Chinese who have work experience in a Japanese-funded enterprise or study abroad. The Japanese emphasizes the control of 
results, and the internal management of the enterprise will be closer to the Chinese culture.

\section{SOUTH KOREAN CULTURE AND THE DILEMMA OF CROSS-CULTURAL MANAGEMENT OF ENTERPRISES}

Historically, South Korea is also a country deeply influenced by Chinese traditional culture. The two countries have similarities in culture. Regarding the cultural power distance, South Korea's cultural power distance is higher than that of China, and corporate leaders or senior leaders have a higher awareness of power, and corporate internal management is more prone to present bureaucracy. South Korea is also a collectivist country, and the interests of organizations or collectives are greater than individual interests. The interests of the organization are almost always put first. The formation of collective interests is embodied in interpersonal relationships, regions, kinship, and educational relationships. For example, the family is an interest group; the relationship between graduates of the same school that enter the same company is a relationship of joint education; people in the same area are more likely to gather together to form an interest group of mutual assistance. South Korea's masculinity culture is higher than that of China, which is similar to Japan. When men and women have the conflicts, they often negotiate with each other to solve problems. South Korean culture has a relatively low acceptance of uncertainty, and corporate senior managers are more able to accept certain results. In recent years, the acceptance of uncertainty has changed due to the influence of the international environment. Because of its low acceptance of uncertainty, Korean culture is more inclined to accept short-term strategies.

There are many Korean-funded enterprises in Yanbian area of Jilin [5], and the most obvious problem they face is the loss of Chinese employees. First, there are difficulties in language communication. There are many ethnic Koreans in Yanbian area, and they also speak Korean. However, with the influence of regional language habits, there is a difference between the choice of words and the pronunciation of the same thing or point of view. Korean employees mostly use Korean language habits, which can easily cause misunderstandings in communication between the two parties. Second, the concentration of power in Korean culture is very obvious in corporate culture. For example, if the superior does not leave the company, the employees will not leave the company even at the closing time. For Chinese employees, they think that this is unreasonable behavior. Third, Korean-funded enterprises usually adopt the model used by Korean companies for employee relationship management and performance appraisal. Chinese employees generally react too harshly and fail to conduct humanized management of employees. As a result, enterprises spend money, material resources, and time to train employees, but employees cannot serve the company for a long time, which increases the company's operating costs. In the internal management of the head office and branch office of a Korean-funded enterprise, the head office is usually the top priority, and the branch office is the second. As a result, the resource allocation will be tilted, which will lead to a lower sense of achievement and insufficient work motivation for the staff of the branch office.

\section{CROSS-CULTURAL MANAGEMENT STRATEGIES FOR NORTHEAST ASIAN ENTERPRISES}

Through the above analysis, it can be seen that the countries in Northeast Asia have similarities in culture, laying the foundation for cooperation between countries or enterprises in the region. At the same time, different countries have different understandings of similar cultures due to differences in values, which is a difficult point in cross-cultural management of enterprises. The difficulty of cross-cultural management of enterprise is manifested in the poor language communication. It does not mean that the two parties cannot communicate through language, but that they have a different understanding of what the language means. When the two parties have different understandings of the same thing, it requires both parties to have creative changes to solve the problem, not just a unilateral compromise through the suppression of rights. Unilateral compromise is not sustainable.

The countermeasures and suggestions for the crosscultural management of Northeast Asian enterprises mainly include five aspects. First, it is supposed to adhere to the principle of common reasons based on the general history of mankind to establish the foundation of enterprise management. For example, the principle of fairness and the principle of "working more and getting more rewards" are all recognized by mankind. The establishment of management mechanisms based on such common reasons is conducive to the recognition and support of employees in a short period of time, and it is more conducive to the long-term development of the company. Second is to increase training in the culture of the host country. Increasing training in the culture of the host country can allow foreign employees to better integrate into the local cultural atmosphere, help foreign employees better understand the incomprehensible phenomena in daily work or life, and help increase the time that foreign employees work for the company. At the same time, the training methods should be more active, such as team building or completing tasks, not just in the form of lectures. Training activities can be combined with employee benefits to achieve high efficiency in 
corporate internal training. Third, when establishing the corporate culture, it is recommended to establish an open and inclusive corporate culture, to promote discussion and problem-solving based on facts, not to involve other contents other than problems. It is suggested to find out the different advantages of each country and integrate them into the daily management of the enterprise. Fourth, it is not recommended to copy the management system of the home company. Companies established in different regions should have their own cultural characteristics, rather than being a subsidiary that is exactly the same as the home company. Fifth, it is recommended to select employees with multicultural backgrounds as management reserve talents. Employees with multicultural backgrounds have better adaptability, broader thinking and perspective, and are more likely to deal with cultural communication issues and emergencies.

\section{CONCLUSION}

To sum up, cross-cultural management of enterprises of Northeast Asia is feasible. Enterprises in different countries have a common cultural foundation, and cultural differences in different countries can complement each other to achieve cultural integration and cultural win-win. With the continuous deepening of globalization and the increase of uncertain factors in the global economy, cross-regional cooperation between enterprises is one of the important ways to achieve long-term mutual benefit.

\section{References}

[1] Hofstede, G. Culture's consequences-International differences in work-related values[M]. SAGE Publications, Inc., Newbury Park, 1984, 132-135.

[2] Jia Hua. Reflections on the dual structure of Japanese culture on the differences between Chinese culture and Japanese culture [J]. Cultural Construction, 2010(3):163-164. (in Chinese)

[3] Sun Yongbo.Crossculture Management Multinational Corporation [J]. Commercial Research, 2008(5): 46-48. (in Chinese)

[4] Wang Chongfeng, Su Rong. The Development of Korean Enterprises in Qingdao from the Perspective of Cultural Fusion [J]. Journal of Shandong University (Philosophy and Social Sciences Edition), 2011(03): 20. (in Chinese)

[5] Sun Xiheng, Dou Shuohua, Wu Xiyuan. Research and measures of cross-cultural Management in Japanese funded enterprises in China [J]. Enterprise reform and management,2020(14):208. (in Chinese)

[6] Zhou Yanchun, Lai Desheng.Research on training and Management Innovation of Overseas Graduate Students in China under the background of "One Belt and One Road" $[\mathrm{J}]$. Journal of Educational Development,2020(09):96. (in Chinese) 